\title{
Suppressive Effects of T-412, a Flavone on Interleukin-4 Production in T Cells
}

\author{
Mirim JiN, ${ }^{a, \#}$ Sunyoung PARK, ${ }^{b, \#}$ and Myoung Yun PYO ${ }^{*, b}$ \\ ${ }^{a}$ Lab of Pathology, College of Oriental Medicine, Daejeon University; Daejeon 300-716, Korea: and ${ }^{b}$ College of \\ Pharmacy, Sookmyung Women's University; Seoul 140-742, Korea. $\quad$ Received July 7, 2009; accepted August 24, 2009
}

\begin{abstract}
Interleukin (IL)-4 has been suggested as a molecular therapeutic target to prevent and/or treat various allergic diseases and several flavonoids have been suggested as anti-allergic agents suppressing IL-4 production. In an effort to find novel candidates for anti-allergic agents from natural sources, we screened several flavonoids affecting on IL-4 production. In this study, we showed that 7,8,4'-trihydroxyflavone (T-412) significantly decreased IL-4 production both in phorbol 12-myristate 13-acetate (PMA) and ionomycin (PI)-activated EL-4 T cells and concanavalin A (ConA)-activated murine $\mathrm{CD}^{+} \mathrm{T}$ cells in a dose- and time-dependent manner. The PI-induced increase of IL-4 mRNA expression was dramatically suppressed by T-412 at $6 \mathrm{~h}$, indicating the suppression is regulated at transcriptional level. T-412 also significantly inhibited IL-4 gene promoter activity in EL-4 T cells transiently transfected with luciferase reporter plasmid containing IL-4 promoter (pGL4.14-IL-4). Western blot analysis of the transcription factors revealed that T-412 suppressed the nuclear expression of nuclear factor of activated $T$ cells (NF-AT)c1, c-Jun and c-Maf, but not c-Fos and nuclear factor kappa B (NF- $k$ B). Our data suggested that T-412 might have potential as a candidate for anti-allergic agent having suppressive effects on IL-4 production in activated $T$ cells by controlling the transcription of IL-4.
\end{abstract}

Key words 7,8,4' -trihydroxyflavone; flavone; interleukin-4; $\mathrm{T}$ cell; anti-allergic agent

Flavonoids are comprised of a large group of low molecular weight polyphenolic compounds having diverse pharmacological effects, ${ }^{1,2}$ and among them their possible use as anti-allergic agents have been proposed..$^{3-5)}$ Intakes of naturally occurring flavonoids have been reported to reduce the allergic symptoms and severities in human ${ }^{6}$ as well as development of allergic diseases in animals, ${ }^{7)}$ and it was suggested that the effects might be mediated by the suppression of immune responses caused by Th2 dominance. ${ }^{5-7)}$

Interleukin (IL)-4 is a representative Th2 cytokine, which is mainly produced by activated Th2 cells. IL-4 not only initiates the development of Th2 cells from Th0 cells but also induces IgE class switching in B cells, resulting in unbalanced Th2 skewing immune system. ${ }^{8}$ Furthermore, it plays a central role in the pathogenesis of various allergic inflammations by promoting production of proinflammatory cytokines such as IL-5 and IL-13. ${ }^{9,10)}$ The expression of IL-4 is tightly regulated at the transcriptional level. The inducible transcription factors including nuclear factor of activated T cells (NFAT), activating protein-1 (AP-1), nuclear factor-kappa B $(\mathrm{NF}-\kappa \mathrm{B})$ as well as c-Maf have been identified to control IL4 and their cooperative interactions on the promoter appears to be critical to induce IL-4 expression in T cells. ${ }^{11,12)}$ Upon $\mathrm{T}$ cell activation by PMA and ionomycin (PI), cytoplasmic NF-ATs are dephosphorylated and translocated to the nucleus; the dephosphorylated proteins show increased affinity for P sites (from P0 - P4), DNA binding sites of NF-ATs, ${ }^{13-}$ ${ }^{15)}$ which is mediated by increased calcium concentration and protein kinase C (PKC)-RAS signaling pathways. ${ }^{16)}$ NF-AT and AP-1 protein (c-Fos and c-Jun) coordinately bind the P1 site, which is required for full activity of the IL-4 promoter. ${ }^{17-19)} \mathrm{NF}-\kappa \mathrm{B}$, generally consisting of p65-p50 dimer, is sequestered into an inactive form by the cytoplasmic inhibitor of NF- $\kappa \mathrm{B}(\mathrm{I} \kappa \mathrm{B})$ in resting $\mathrm{T}$ cells, however active forms of NF- $\kappa$ B translocate to nucleus, where the IL-4 expression is regulated together with other transcription factors. ${ }^{20)}$ Furthermore, the proto-oncogene c-Maf, which is expressed in Th2 cells but not in Th1 cells, binds to a c-Maf response element (MARE) adjacent to a P0 site in synergy with the NF-AT to activate IL-4 production. ${ }^{21,22)}$

As an effort to find out novel therapeutics from natural sources we screened the down-regulatory effects of several novel flavonoids on IL-4 using PI-activated EL-4 thymoma, a murine $\mathrm{T}$ cell line. Among them a flavone, named T-412 (7,8,4'-trihydroxyflavone), had significant down-regulatory effects on IL-4 production in a dose- and time-dependent manner, which was accompanied by the suppression of the expression level of IL-4 mRNA. Furthermore, the proximal promoter activities of IL-4 were also suppressed. To understand the mode of action for T-412 at the molecular level when we performed Western blot analysis for selective transcription factors involving in the activation of proximal promoter, the expression of NF-ATc1, c-Jun, as well as c-Maf but not $\mathrm{c}-\mathrm{Fos}$ and NF- $\kappa \mathrm{B}$ were revealed to be suppressed by T-412. Our data suggested that T-412 might have potential as a candidate for anti-allergic agent by inhibiting IL-4 production in activated $\mathrm{T}$ cells.

\section{MATERIALS AND METHODS}

Materials and Cell Culture T-412 was purchased from Indofine chemical company (Hillsborough, NJ, U.S.A.). Phorbol 12-myristate 13-acetate (PMA) and ionomycin were purchased from Sigma (St. Louis, MO, U.S.A.). Cyclosporin A (CsA) was obtained from Calbiochem (La Jolla, CA, U.S.A.), $\mathrm{NIMT}^{\mathbb{B}} \mathrm{FeOfection}$ was purchased from Genovis (Scheelevagen, Lund, Sweden) and luciferase substrate solution was purchased from Promega (Madison, WI, U.S.A.). EL-4 thymoma was purchased from the Korea Cell Bank (Seoul, Korea) and maintained in RPMI-1640 medium (Lonza, Walkersville, MD, U.S.A.) supplemented with $10 \%$ fetal bovine serum (Lonza, Walkersville, MD, U.S.A.) and $100 \mu \mathrm{g} / \mathrm{ml}$ of penicillin-streptomycin (Lonza, Walkersville, $\mathrm{MD}$, U.S.A.) at $37^{\circ} \mathrm{C}$ in a $5 \% \mathrm{CO}_{2}$ humidified air atmo- 
sphere.

Isolation of $\mathrm{CD4}^{+} \mathbf{T}$ Cells Seven to eight week old female BALB/c mice were obtained from Samtako Bio Korea (Gyeonggi-do, Korea). CD4 ${ }^{+} \mathrm{T}$ cells were positively purified from spleen cells of the mice by incubating with anti-mouse CD4 conjugated microbeads (Miltenyi Biotec, Bergisch Gladbach, Germany) for $15 \mathrm{~min}$ at $4{ }^{\circ} \mathrm{C}$. After incubation, the magnetically labeled cells were applied into the magnetic activated cell sorting (MACS) positive selection columns in a VarioMACS (Miltenyi Biotec.) according to the manufacturer's protocol. After washing with a buffer (PBS containing $2 \mathrm{~mm}$ EDTA and $0.5 \%$ bovine serum albumin), the $\mathrm{CD}^{+} \mathrm{T}$ cells were eluted and washed with serum-free RPMI-1640 medium. Flow cytometric analysis using anti-CD4 ${ }^{+}$antibody indicated that over $98 \%$ of isolated cells were CD4 positive.

ELISA EL-4 $\mathrm{T}$ cells $\left(1 \times 10^{6}\right.$ cells $\left./ \mathrm{ml}\right)$ were treated with PMA $(50 \mathrm{ng} / \mathrm{ml})$ and ionomycin $(0.5 \mu \mathrm{M})$ for $16 \mathrm{~h}$ in the absence or presence of flavone. Isolated $\mathrm{CD}^{+} \mathrm{T}$ cells were stimulated for $24 \mathrm{~h}$ with concanavalin A (ConA) in the absence or presence of T-412. The levels of IL-4 in the culture supernatant were determined using a commercially available ELISA kit (BD Science, San Diego, CA, U.S.A.) according to the manufacturer's instruction.

Reverse Transcriptase-Polymerase Chain Reaction (RT-PCR) Total RNAs were isolated by the single-step method using the TRIzol reagent (Invitrogen, Calsbad, CA, U.S.A.). Each sample was reverse-transcribed to cDNA for $60 \mathrm{~min}$ at $42^{\circ} \mathrm{C}$ using a cDNA synthesis kit (iNtRON Biotechnology, Gyeonggi-do, Korea). The sequences of PCR primers are as follows. Mouse IL-4 sense; 5'-ATGGGTCTCAACCCCCAGC-3', mouse IL-4 antisense; 5'-GCTCTTTACGCTTTCCAGGAAGTC-3', $\beta$-actin sense; $5^{\prime}$-TGGAATCCTGTGGCATCCATGAAAC- $3^{\prime}$ and $\beta$-actin antisense; 5'-TAAAACGCAGCTCAGTAACAGTCCG-3'. The PCR reactions were run for 32 cycles for $94^{\circ} \mathrm{C}(30 \mathrm{~s}), 57^{\circ} \mathrm{C}$ $(30 \mathrm{~s}), 72^{\circ} \mathrm{C}(30 \mathrm{~s})$. After the amplification, the RT-PCR products were separated in $1.2 \%(\mathrm{w} / \mathrm{v})$ agarose gel and stained with ethidium bromide. The size of PCR products for IL-4 and $\beta$-actin were 397 and $349 \mathrm{bp}$, respectively.

Quantitative Real-Time Polymerase Chain Reaction EL-4 T cells $\left(1 \times 10^{6}\right.$ cells $\left./ \mathrm{ml}\right)$ were pretreated with vehicle or $25 \mu \mathrm{M}$ of $\mathrm{T}-412$ for $1 \mathrm{~h}$, and then stimulated with PMA $(50 \mathrm{ng} / \mathrm{ml})$ and ionomycin $(0.5 \mu \mathrm{M})$ for 3,6 and $9 \mathrm{~h}$. Total RNAs were isolated by using TRIzol reagent (Invitrogen, Calsbad, CA, U.S.A.) as the manufacturer's recommendations. The RNA samples were used for cDNA synthesis by using M-MLV reverse transcriptase (Promega, Madison, WI, U.S.A.). Real-time PCR was conduced on Rotor-Gene 6000 (Corbett research, Australia) using iQ SYBR green supermix (Bio-Rad, Hercules, CA, U.S.A.) with mouse IL-4 and $\beta$ actin specific primers under the following conditions: initial denaturation for $3 \mathrm{~min}$ at $95^{\circ} \mathrm{C}$, denaturation for $10 \mathrm{~s}$ at $95^{\circ} \mathrm{C}$, annealing for $20 \mathrm{~s}$ at $60^{\circ} \mathrm{C}$ and extension for $20 \mathrm{~s}$ at $72^{\circ} \mathrm{C}$ by 40 cycles. Mouse IL-4 sense; $5^{\prime}$-AGCCATATCCACGGATGCGA, mouse IL-4 antisense; 5'-TGGCGTCCCTTCTCCTGTGA, $\beta$-actin sense; $5^{\prime}$-CGGGGACCTGACTGACTACC, and $\beta$-actin antisense; 5'-AGGAAGGCTGGAAGAGTGC.

Transient Transfection and Luciferase Assay The reporter plasmid (pGL4.14-IL-4) containing IL-4 promoter region extending from -741 to +56 was previously generated by us. ${ }^{23)}$ EL- 4 T cells $\left(4 \times 10^{5}\right.$ cells $\left./ \mathrm{ml}\right)$ were transfected with pGL4.14-IL-4 (0.3 $\mu \mathrm{g}$ of DNA per well) using NIMT ${ }^{\circledR} \mathrm{FeO}$ fection according to the manufacturer's protocol. After $28 \mathrm{~h}$ of transfection, the cells were treated with PMA $(50 \mathrm{ng} / \mathrm{ml})$ and ionomycin $(0.5 \mu \mathrm{M})$ for $16 \mathrm{~h}$ in the absence or presence of T-412. The cells were harvested and washed with PBS three times and cell lysates were extracted with $100 \mu \mathrm{l}$ of lysis reagent (Promega, Madison, WI, U.S.A.). The lysates were mixed with $100 \mu \mathrm{l}$ of luciferase substrate solution (Promega, Madison, WI, U.S.A.), and the emitted light was measured using an Lmax 11 luminometer (Molecular Devices, Sunnyvale, CA, U.S.A.).

Western Immunoblot Analysis EL-4 T cells $\left(1 \times 10^{6}\right.$ cells $/ \mathrm{ml})$ were pretreated with $1 \mu \mathrm{M}$ of CsA or T-412 $(25 \mu \mathrm{M})$ for $1 \mathrm{~h}$ and then stimulated with PMA $(50 \mathrm{ng} / \mathrm{ml})$ and ionomycin $(0.5 \mu \mathrm{M})$ at $37^{\circ} \mathrm{C}$ in a $5 \%$ incubator for 30 or $120 \mathrm{~min}$. Cytoplasmic extract and nuclear extract were obtained using Nuclear extract kit (Active Motif, Carlsbad, CA, U.S.A.) as manufacturer's recommendations. In brief, the cells were washed with ice-cold PBS and centrifugation at $400 \times \boldsymbol{g}$ for $5 \mathrm{~min}$ at $4^{\circ} \mathrm{C}$, resuspended in $250 \mu \mathrm{l}$ of hypotonic buffer. The cells were allowed to swell on ice for $15 \mathrm{~min}$, lysed gently with $12.5 \mu \mathrm{l}$ of detergent reagent. After centrifugation at $14000 \times \boldsymbol{g}$ for $1 \mathrm{~min}$ at $4^{\circ} \mathrm{C}$, the supernatant was acquired in the form of a cytoplasmic extract. The nuclear extract was subsequently gathered by resuspending the nuclear pellet in $25 \mu \mathrm{l}$ of complete lysis buffer. After $30 \mathrm{~min}$ on ice, the suspension was centrifuged for $10 \mathrm{~min}$ at $14000 \times \boldsymbol{g}$ and $4{ }^{\circ} \mathrm{C}$, the supernatant was acquired in the form of a nuclear extract. The quantity of protein in the cytoplasmic and nuclear extract was evaluated by using BCA protein assay (Pierce, Rockford, IL, U.S.A.). The subcellular extracts were separated on $10 \%$ SDS-PAGE, transferred to nitrocellulose membranes (Amersham Biosciences, Piscataway, NJ, U.S.A.) and blocked with 5\% skim milk in PBS/T buffer for $1 \mathrm{~h}$. The nitrocellulose membrane was then incubated with specific antibodies against NF-ATc1, c-Maf, NF- $\kappa$ B p65, c-Jun and c-Fos (Santa Cruz Biotechnology, Santa Cruz, CA, U.S.A.). Blots were incubated with HRP-conjugated secondary antibody. HRP was detected using a chemiluminescent detection reagent (Amersham Biosciences, Piscataway, NJ, U.S.A.).

\section{RESULTS}

T-412 Inhibits IL-4 Production in Activated T Cells To test the effects of T-412 (chemical structure, Fig. 1) on IL-4 production in T cells, EL-4 T cells were stimulated with PI in the absence or presence of T-412 without affecting cell viability. Upon PI-stimulation IL-4 productions were gradually increased in a time-dependent manner (Fig. 2A). However, in the presence of T-412 at the concentration of $25 \mu \mathrm{M}$ the increase was greatly suppressed; resulting in a decrease

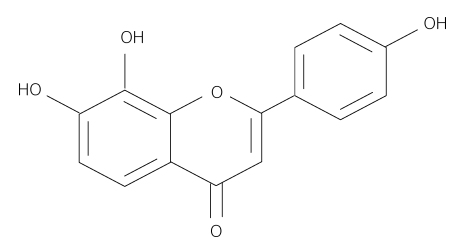

Fig. 1. Chemical Structure of T-412 
in the production by levels similar to that of normal cells at $16 \mathrm{~h}$ (Fig. 2B). When the cells were treated with T-412 at the varying concentrations the PI-induced IL-4 productions were significantly suppressed in a dose-dependent manner as shown in Fig. 2B, which was not the cytotoxic effects of T412 as it did not affect cell viability at all used concentrations. CsA $(1 \mu \mathrm{M})$, a well known immunosuppressive agent, used as a positive control, almost completely inhibited IL-4 production as previously reported. ${ }^{23,24)}$ Additionally, we labored the $\mathrm{CD}^{+} \mathrm{T}$ cells to confirm the suppressive effects of $\mathrm{T}-412$ in primary $\mathrm{T}$ cells. The $\mathrm{CD}^{+} \mathrm{T}$ cells were isolated from murine spleen and stimulated with ConA. As shown in Fig. $2 \mathrm{C}$ the treatment with $\mathrm{T}-412$ significantly inhibited the IL-4 production in $\mathrm{CD}^{+}{ }^{+} \mathrm{T}$ cells. Our data indicated that T412 has suppressive effects on IL-4 production in activated $\mathrm{T}$ cells.

T-412 Inhibits IL-4 mRNA Expression in Activated T Cells To determine whether the inhibition of IL-4 production by $\mathrm{T}-412$ is the result of decreased mRNA production, the levels of IL-4 mRNA were assessed in the PI-stimulated EL-4 T cells using real-time PCR. As shown in Fig. 3A treatment with PI dramatically increased IL-4 mRNA and peaked following $6 \mathrm{~h}$, resulting in approximately a 5-fold increase compared with that of normal cells. In the presence of T-412 the increase was highly suppressed, and the levels of IL-4 mRNA were maintained similar to those of control, indicating that the inhibition of IL-4 production by T-412 occurred at the transcriptional level. Consistently, RT-PCR product for IL-4 from the T-412 treated cells showed that there was an almost complete inhibition in the IL-4 mRNA expression at $6 \mathrm{~h}$ (Fig. 3B), however T-412 did not affect $\beta$-actin mRNA expression in PI-stimulated EL-4 T cells, suggesting that the suppressive effects of IL-4 production by T-412 were not the result from a generalized inhibition of cellular activation. These data suggested that T-412 has suppressive effects on IL-4 mRNA expression at the transcriptional level.

T-412 Suppresses PI-Induced IL-4 Promoter Activation In T cells, IL-4 expression is tightly regulated at the tran- scriptional level by diverse regulatory elements within a proximal promoter region. ${ }^{11,12,14)}$ To test whether T-412 has suppressive effects on PI-induced promoter activation, we used luciferase reporter plasmid containing the IL-4 pro-
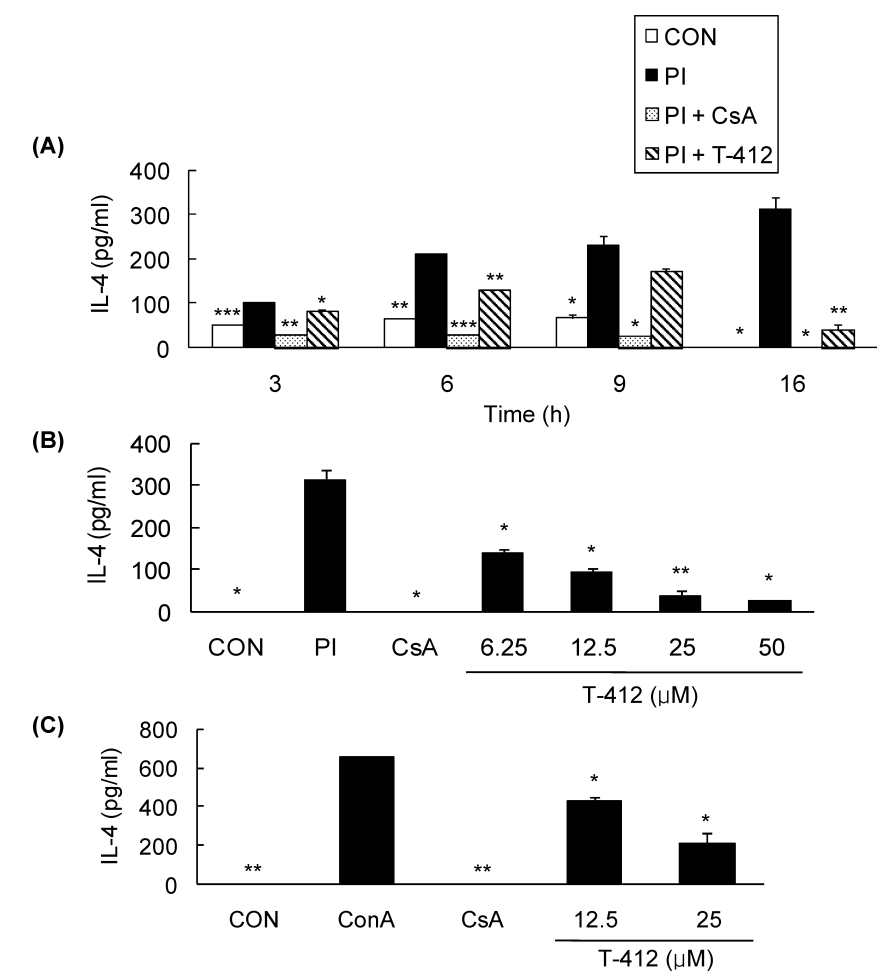

Fig. 2. Suppressive Effects of T-412 on IL-4 Production in Activated T Cells

(A) EL-4 T cells pretreated with $25 \mu \mathrm{m}$ of T-412 or CsA $(1 \mu \mathrm{m})$ for $1 \mathrm{~h}$, and then stimulated with PMA $(50 \mathrm{ng} / \mathrm{ml}) /$ ionomycin $(0.5 \mu \mathrm{M})$ for 3, 6, 9 and $16 \mathrm{~h}$. (B) EL-4 T cells $\left(1 \times 10^{6} \mathrm{cells} / \mathrm{ml}\right)$ were pretreated with $\mathrm{T}-412$ at the indicated concentrations for $1 \mathrm{~h}$, and then stimulated with PMA $(50 \mathrm{ng} / \mathrm{ml}) /$ ionomycin $(0.5 \mu \mathrm{M})$ for $16 \mathrm{~h}$. (C) $\mathrm{CD} 4+$ $\mathrm{T}$ cells isolated from murine spleen were pretreated with T-412 at the indicated concentrations for $1 \mathrm{~h}$, and then stimulated with ConA $(5 \mu \mathrm{g} / \mathrm{ml})$ for $24 \mathrm{~h}$. The supernatants were collected, and the levels of IL-4 were determined by ELISA. Values are expressed as means \pm S.D. from three-independent experiments. $* p<0.05, * * p<0.01, * * * p<$ 0.001 vs. PI- or ConA-treated control.

(A)

\begin{tabular}{cccc}
\hline Time $(\mathrm{h})$ & 3 & 6 & 9 \\
\hline CON & $49.2 \pm 5.61^{*}$ & $20.3 \pm 19.5^{*}$ & $52.1 \pm 9.93^{*}$ \\
PI & 100 & 100 & 100 \\
CsA & $16.2 \pm 11.0^{*}$ & $2.94 \pm 0.67^{\star \star *}$ & $21.0 \pm 13.7^{\star}$ \\
T-412 & $33.6 \pm 27.5$ & $27.6 \pm 14.0^{*}$ & $66.7 \pm 7.73^{\star}$ \\
\hline
\end{tabular}

(B)

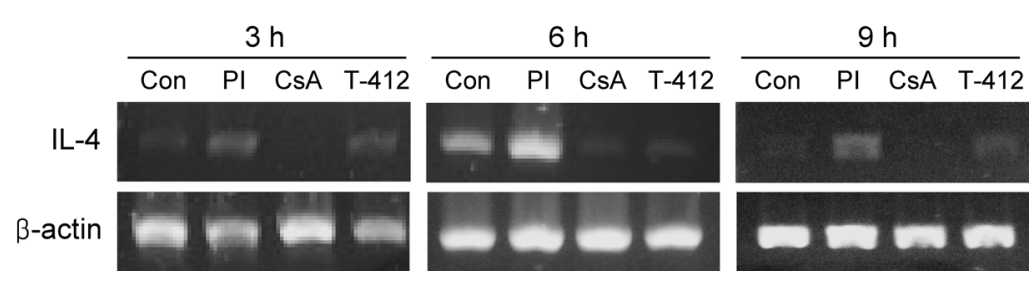

Fig. 3. Suppressive Effect of T-412 on IL-4 mRNA Expression in Activated T Cells

EL-4 T cells were pretreated with $25 \mu \mathrm{M}$ of T-412 or CsA $(1 \mu \mathrm{M})$ for $1 \mathrm{~h}$, and then stimulated with PMA $(50 \mathrm{ng} / \mathrm{ml}) /$ ionomycin $(0.5 \mu \mathrm{M})$ for 3 , 6 and $9 \mathrm{~h}$. (A) The levels of IL-4 mRNA were determined by quantitative real-time PCR. (B) The expression of IL-4 and $\beta$-actin mRNA was examined by means of RT-PCR. Relative activities are calculated by comparing with the PI-treated group. Values are expressed as means \pm S.D. from three-independent experiments. $* p<0.05, * * * p<0.001 v s$. PI-treated group. 
moter sequences from -741 to +56 . EL-4 T cells transiently transfected with this plasmid were stimulated with PI in the absence or presence of T-412, and the luciferase activities were determined by luminometer. As shown in Fig. 4, T-412 at the concentration of $25 \mu \mathrm{M}$ significantly suppressed the PIinduced promoter activation, which was comparable to that of CsA treated cells at the concentration of $1 \mu \mathrm{M}$. These results suggested that T-412 has suppressive effects on PIinduced IL-4 promoter activation.

Effects of T-412 on Selective Transcription Factors Controlling IL-4 Promoter The proximal promoter of IL4 has multiple binding sites for members of the NF-AT family of transcription factors, termed $\mathrm{P}$ elements ${ }^{14,19)}$ and the other transcription factors including AP-1, NF- $\kappa \mathrm{B}$ as well as c-Maf, also interact with their respective specific target sites in the promoter region to induce IL-4 expression. ${ }^{11,12,14)}$ To investigate whether the suppression of the IL-4 promoter activation is mediated by transcription factors we examined the levels of selective transcription factors. The levels of NF-AT, AP-1 (c-Jun and c-Fos), NF- $\kappa$ B (p65), as well as c-Maf in both the cytoplasm and the nucleus were determined using Western blot analysis. In control, most transcription factors maintained low levels but the treatment with PI highly in-

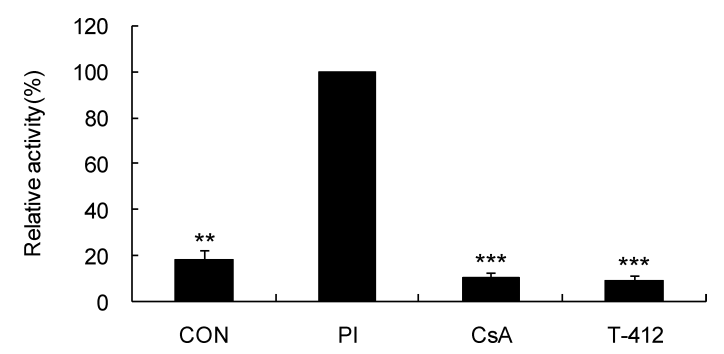

Fig. 4. Suppressive Effects of T-412 on IL-4 Promoter Activation

EL-4 T cells were transiently transfected with pGL4.14-IL-4 luciferase reporter plasmid containing IL-4 proximal promoter $(-741$ to +56$)$. The cells were pretreated with $25 \mu \mathrm{M}$ of T-412 or CsA $(1 \mu \mathrm{M})$ for $1 \mathrm{~h}$, and then stimulated with PMA $(50 \mathrm{ng} / \mathrm{ml}) /$ ionomycin $(0.5 \mu \mathrm{M})$ for $16 \mathrm{~h}$. The luciferase activities were measured by luminometer. Relative activities are calculated by comparing with luciferase activity of control. Values are expressed as means \pm S.D. from three-independent experiments. $* * p<0.01$ $* * * p<0.001$ vs. PI-treated group creased the productions of the diverse transcription factors as shown in Fig. 5. The treatment with T-412 significantly decreased the nuclear location of NF-ATc1 following $120 \mathrm{~min}$ treatments without affecting the expression of cytoplasmic NF-ATc1, indicating that T-412 might block the nuclear localization of NF-ATc1 (Fig. 5A). When c-Fos and c-Jun, the components of AP-1 were examined, the level of c-Jun was significantly decreased in the nucleus but not in the cytoplasm, indicating nuclear localization of the protein was inhibited by T-412 (Fig. 5B). In contrast, the level of c-Fos in the nucleus was not affected at all, and cytoplasmic c-Fos was not detected as expected because c-Fos is mainly present in the nucleus (Fig. 5C). ${ }^{25)}$ Interestingly, the PI-induced production of c-Maf was significantly suppressed by the levels of normal in the presence of T-412 (Fig. 5D), and the suppression was prominent in the nuclear extract, approximately $50 \%$ reduction in band density compared with that of PItreated cells at $120 \mathrm{~min}$, but the changes were insignificant in the cytoplasm, suggesting that T-412 might suppress the nuclear expression of c-Maf. On the contrary, the nuclear expression of $\mathrm{p} 65$, a component of $\mathrm{NF}-\kappa \mathrm{B}$, was not affected by T-412 (Fig. 5E). CsA ( $1 \mu \mathrm{M})$, a potent immunosuppressive agent used as a positive control, decreased the nuclear production of NF-ATc1, c-Jun, and NF- $\kappa \mathrm{B}$ as previously reported $^{13,23,26)}$ and c-Maf production was also suppressed. These data suggested that T-412 might inhibit IL-4 production via suppression of selective transcription factors including NF-AT, AP-1, as well as c-Maf but not NF- $\kappa$ B.

\section{DISCUSSION}

While the prevalence of allergic disease including atopic dermatitis, asthma, and rhinitis is being steeply increased in westernized countries, there is a lack of safe and effective anti-allergic agents. Anti-histamines are only effective in lessening sleep disturbance ${ }^{27)}$ and systemic corticosteroids are effective in adult allergic patients but rebound and diminishing effectiveness limit their use. ${ }^{28)}$ Cyclosporin A, an immunosuppressive agent, is permitted for use in severe disease

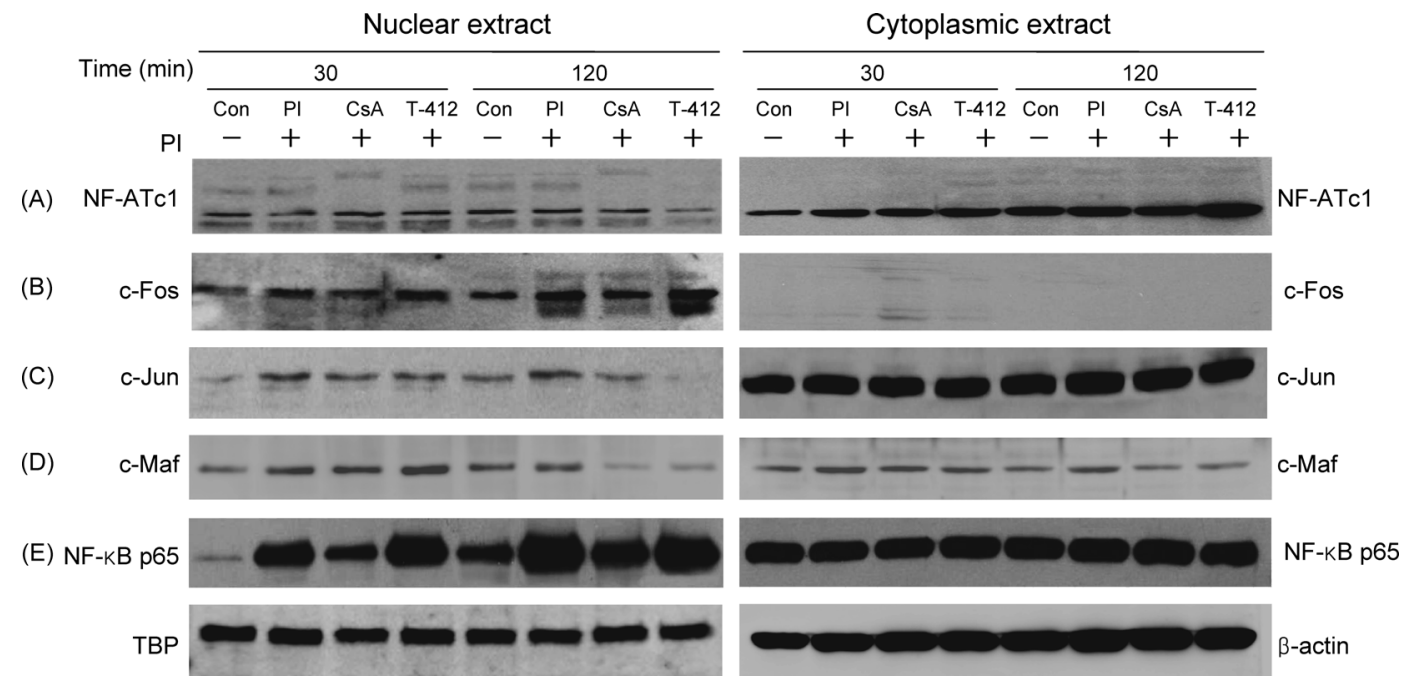

Fig. 5. Effects of T-412 on the Transcription Factors Involved in IL-4 Expression

EL-4 T cells were pretreated with $25 \mu \mathrm{M}$ of T-412 or CsA $(1 \mu \mathrm{M})$ for $1 \mathrm{~h}$, and then stimulated with PMA $(50 \mathrm{ng} / \mathrm{ml}) /$ ionomycin $(0.5 \mu \mathrm{M})$ for 30 or 120 min. Both nuclear and cytoplasmic extracts were prepared as described in Materials and Methods, and electrophoresed by SDS-PAGE. The levels of (A) NF-ATc1, (B) c-Jun, (C) c-Fos, (D) c-Maf, (E) NF- $\kappa$ B p65 proteins were determined by Western blot analysis using specific antibodies. TBP and $\beta$-actin were used as a loading control for nucleus and cytoplasm, respectively. The data presented are representative of three independent experiments. 
status; however, it has been associated with severe toxicity due to its ability to inhibit calcineurin in cells outside the immune system. ${ }^{13,29,30)}$ Therefore, developing safe and effective pharmacological agent is definitely needed.

Since IL-4 plays pivotal pathologic roles in various allergic diseases, ${ }^{1,7,11)}$ the suppression of IL-4 expression has been suggested as a molecular therapeutic target to prevent and/or treat allergy. ${ }^{31)}$ Naturally occurring flavonoids with safety have attracted considerable attention as anti-allergic agents ${ }^{5)}$ suppressing Th2 cytokine production in T cells ${ }^{32)}$ as well as basophils, ${ }^{33)}$ and intake of flavonoids has been known to reduce the incidence and severity of allergies in humans. ${ }^{5,6)}$

In this study we showed that $25 \mu \mathrm{M}$ of T-412 almost completely inhibited IL-4 production in activated T cells without affecting cell viability. T-412 suppressed the IL-4 expression at the transcriptional level, and we found that T-412 could control the selective transcription factors including NFAT/AP-1 and c-Maf but not NF- $\kappa$ B. As the nuclear expressions of NF-ATc1 and c-Jun were greatly blocked following 120 min of treatment of T-412 without suppression on the cytoplasmic expression of the transcription factors, the nuclear translocation seemed to be impeded by $\mathrm{T}-412$, resulting in the suppression of IL-4 promoter activation. Based on the facts that both PI induces several signaling pathways leading to NF-ATc1 and c-Jun activation and nuclear translocation, ${ }^{16,17,34)}$ and that IL-4 promoter contains five NF-AT/AP-1 composite binding sites while the expression of IL-4 mRNA is absolutely dependent on cooperation between NF-AT and AP- $1,{ }^{18)}$ we imagine that T-412 might interfere with the PIinduced signaling pathway leading to NF-ATc1 and AP-1 activation for IL-4 expression, and that the detailed mechanisms remain to be understood in the near future. Furthermore, our data are especially interesting in the suppression of c-Maf expression by T-412. The proto-oncogene c-Maf, a member of the bZIP family, which is specifically expressed in Th2 cells, ${ }^{11,21,22)}$ is known to be responsible for the selective expression of IL-4 by synergistically interacting with NF-AT but not other Th2 cytokines such as IL-5 and IL$13 .^{35)}$ To our knowledge there is no flavonoid having suppressive effects on c-Maf to down-regulate IL-4 expression. On the other hand, CsA indiscriminately suppressed the activation of various transcription factors including $\mathrm{NF}-\kappa \mathrm{B}$ as well as NF-ATc1, AP-1, and c-Maf, but T-412 showed no effects on NF- $\kappa \mathrm{B}$ activation when determined on the expression of p65. Taken together, T-412 might be a candidate for an antiallergic agent having unique features and novel mechanisms controlling IL-4 rather than an immunosuppressive agent generally suppressing $\mathrm{T}$ cell activation. For the first time our study indicated that T-412 might have some potential as a novel therapeutic for allergies. Considering the global prevalence of allergic disease and limitation of current therapeutics, further investigation of both safety and efficacy studies for T-412 is warranted.

Acknowledgment This work was supported by the SRC Research Center for Women's Diseases of Sookmyung Women's University.

\section{REFERENCES}

1) Harborne J. B., Williams C. A., Phytochemistry, 55, 481-504 (2000).

2) Middleton E. Jr., Kandaswami C., Theoharides T. C., Pharmacol. Rev., 52, 673-751 (2000).

3) Middleton E. Jr., Kandaswami C., Biochem. Pharmacol., 43, 11671179 (1992).

4) Tanaka T., Higa S., Hirano T., Kotani M., Matsumoto M., Fujita A., Curr. Med. Chem.-Anti-inflammation \& Anti-allergy Agents, 2, 57$65(2003)$

5) Kawai M., Hirano T., Higa S., Arimitsu J., Maruta M., Kuwahara Y., Ohkawara T., Hagihara K., Yamadori T., Shima Y., Ogata A., Kawase I., Tanaka T., Allergol. Int., 56, 113-123 (2007).

6) Garcia V., Arts I. C., Sterne J. A., Thompson R. L., Shaheen S. O., Eur. Respir. J., 26, 449-452 (2005).

7) Kotani M., Matsumoto M., Fujita A., Higa S., Wang W., Suemura M., Kishimoto T., Tanaka T., J. Allergy Clin. Immunol., 106, 159-166 (2000).

8) O'Garra A., Immunity, 8, 275-283 (1998)

9) Tepper R. I., Levinson D. A., Stanger B. Z., Campos-Torres J., Abbas A. K., Leder P., Cell, 62, 457-467 (1990).

10) Ricci M., Matucci A., Rossi O., J. Investig. Allergol. Clin. Immunol., 7, 144-150 (1997).

11) Agnello D., Lankford C. S., Bream J., Morinobu A., Gadina M., O’Shea J. J., Frucht D. M., J. Clin. Immunol., 23, 147-161 (2003).

12) Rengarajan J., Szabo S. J., Glimcher L. H., Immunol. Today, 21, 479483 (2000).

13) Rao A., Luo C., Hogan P. G., Annu. Rev. Immunol., 15, 707-747 (1997).

14) Szabo S. J., Glimcher L. H., Ho I. C., Curr. Opin. Immunol., 9, 776781 (1997).

15) Li-Weber M., Salgame P., Hu C., Davydov I. V., Laur O., Klevenz S., Krammer P. H., J. Immunol., 161, 1380-1389 (1998).

16) Crabtree G. R., Cell, 96, 611-614 (1999).

17) Li B., Tournier C., Davis R. J., Flavell R. A., EMBO J., 18, 420-432 (1999).

18) Rooney J. W., Hoey T., Glimcher L. H., Immunity, 2, 473-483 (1995).

19) Takemoto N., Koyano-Nakagawa N., Arai N., Arai K., Yokota T., Int. Immunol., 9, 1329-1338 (1997).

20) Li-Weber M., Giaisi M., Baumann S., Palfi K., Krammer P. H., Eur. J. Immunol., 34, 1111-1118 (2004).

21) Ho I. C., Hodge M. R., Rooney J. W., Glimcher L. H., Cell, 85, $973-$ 983 (1996).

22) Kim J. I., Ho I. C., Grusby M. J., Glimcher L. H., Immunity, 10, 745751 (1999).

23) Choi J. J., Park B. K., Song G. Y., Kim J. S., Kim J. H., Kim D. H., Jin M., Arch. Pharm. Res., 30, 1102-1110 (2007).

24) Higa S., Hirano T., Kotani M., Matsumoto M., Fujita A., Suemura M., Kawase I., Tanaka T., J. Allergy Clin. Immunol., 111, 1299-1306 (2003).

25) Malnou C. E., Salem T., Brockly F., Wodrich H., Piechaczyk M., Jariel-Encontre I., J. Biol. Chem., 282, 31046-31059 (2007).

26) Proksch P., Giaisi M., Treiber M. K., Palfi K., Merling A., Spring H., Krammer P. H., Li-Weber M., J. Immunol., 174, 7075-7084 (2005).

27) Klein P. A., Clark R. A., Arch. Dermatol., 135, 1522-1525 (1999).

28) Sidbury R., Hanifin J. M., Clin. Exp. Dermatol., 25, 559-566 (2000).

29) Sowden J. M., Berth-Jones J., Ross J. S., Motley R. J., Marks R., Finlay A. Y., Salek M. S., Graham-Brown R. A., Allen B. R., Camp R. D., Lancet, 338, 137-140 (1991).

30) Behnam S. M., Behnam S. E., Koo J. Y., J. Drugs Dermatol., 4, 189194 (2005).

31) Steinke J. W., Immunol. Allergy Clin. North Am., 24, 599-614 (2004).

32) Park J., Kim S. H., Kim T. S., Immunol. Lett., 103, 108-114 (2006).

33) Hirano T., Higa S., Arimitsu J., Naka T., Shima Y., Ohshima S., Fujimoto M., Yamadori T., Kawase I., Tanaka T., Int. Arch. Allergy Immunol., 134, 135-140 (2004).

34) Guo L., Urban J. F., Zhu J., Paul W. E., J. Immunol., 181, 3984-3993 (2008).

35) Weigmann B., Nemetz A., Becker C., Schmidt J., Strand D., Lehr H. A., Galle P. R., Ho I. C., Neurath M. F., J. Immunol., 173, 3446-3455 (2004). 